\title{
Pattern of Analgesic use and Perception of Pain Management by Health Care Workers in a Medical Facility
}

\author{
Rebecca O. Soremekun ${ }^{1 *}$, Oladipupo K. Ogunjuyigbe ${ }^{2}$, Ebele E. Onwuchuluba ${ }^{1}$ \\ ${ }^{1}$ Department of Clinical Pharmacy, Faculty of Pharmacy, University of Lagos, Nigeria. \\ ${ }^{1}$ University of Lagos Medical Center, Akoka, Lagos, Nigeria.
}

\section{ARTICLE INFO \\ Article history: \\ Received on: 17/03/2016 \\ Revised on: 22/06/2016 \\ Accepted on: 17/07/2016 \\ Available online: 29/11/2016}

Key words:

Pain management,

Analgesics, Prescribing

Pattern, Pain perception.

\begin{abstract}
Background and objectives: Though analgesics are the main stay in pain management, physicians' knowledge on pain assessment and treatment modalities could affect the management. This study sought to evaluate pattern of analgesics prescription, healthcare professionals' knowledge and perception of pain and its management in a secondary healthcare facility.

Methods: This was a descriptive retrospective review of 16,365 prescriptions of patients within the medical facility for six months to evaluate drugs used in pain management. Cross-sectional survey of 50 healthcare professionals' knowledge and perception of pain management in the facility was also carried out through the use of a questionnaire.

Results: 4,323 (26.42\%) prescriptions had no pain medication. 36\% prescriptions had multiple pain medications and non-opioid analgesics (85.4\%) were the most commonly prescribed. Dosage forms prescribed were oral $(91.38 \%)>$ Injectables $(5.08 \%)>$ dermal $(2.9 \%)$. 64\% of health workers perceive pain as closely connected with an underlying illness but were not familiar with standard pain management guideline.

Conclusion: There is a high volume of analgesic use and the non-opioids are the most commonly prescribed in this facility. Health care practitioners connect pain and some other illnesses but standard pain management guidelines were not used.
\end{abstract}

\section{INTRODUCTION}

Pain is among the most common reasons for increased health care utilization (Mantyselka et al., 2001, Clark 2002). The International Association for the study of pain defined pain as an unpleasant sensory and emotional experience associated with actual or potential tissue damage or described in terms of such damage (Pain Clinical Updates, 2011). Pain could be acute or chronic depending on its etiology and can arise due to a pathological condition or can be triggered off by physical, mechanical, thermal, electrical or chemical agents (Beers et al., 1999; Kaye et al., 2010). The prevalence of pain (among patients) ranges from $15-50 \%$ and is considered the fifth vital

\footnotetext{
* Corresponding Author

Email: rebeccasoremekun@yahoo.com
}

sign in disease conditions in most developing countries including Nigeria (Smith et al., 2001, Pain Clinical Updates, 2011). Patients who seek healthcare for pain are more likely to have; an anxiety disorder, significant activity limitations and an unfavorable health perception (Gureje et al., 1998; Gureje et al., 2001). Pain relief had also been described as part of basic human rights to health, as uncontrolled pain can lead to delay in healing process, prolonged hospital admissions, an increased risk of developing chronic pain, increased stigma and loss in productive work time (Brennan and Cousins, 2004). Headache had been reported as the most common pain condition resulting in lost productive time especially in form of reduced productive output (Gourlay et al., 2005; Stewart, et al., 2003). Pain is a subjective phenomenon which means it cannot be measured quantitatively. It is whatever the experiencing person says it is and existing whenever and wherever he/she says it does (McCaffery and Beebe, 1994). 
The perception of pain also differs across the different age groups with increasing incidence and prevalence among the elderly patients. It may be underreported especially by elderly patients since they incorrectly perceive pain as a normal process of aging (Roumie and Griffin, 2004).

Analgesics are the mainstay in the management of pain and are among the easily abused medications globally because they are available over-the-counter. Opioids, non-opioid analgesics or adjuvants can be used in pain management depending on the intensity of the pain. When inappropriately prescribed or used, analgesics can result in side effects, drug-drug interactions and other adverse effects (Apfelbaum 2003). Despite the substantial advances and availability of various classes of analgesics in pain management, majority of patients still experience inadequate pain control. It has been reported that pain management is less than optimal in many clinical settings (Gordon et al., 2005, Benhamou et al., 2008; Ogboli-Nwasor et al., 2012). Adequate pain management should therefore involve the formulation of a structured, multilevel systems approach that will ensure prompt recognition and treatment, regular reassessment with the involvement of the patients and their caregivers. A standardized patient assessment and management approach to pain has resulted in reduced stigma, improved patient care, and reduced overall risk (Public Law 106-386, 2000, Gourlay, 2005). Although the pattern of care and management differs between centers, the physicians' knowledge of analgesic use and perception of treatment modalities determine the way pain is managed in both ambulatory and inpatients. Adequate pain management therefore remains paramount and requires a multidisciplinary and collaborative approach among the healthcare professionals involved in managing pain symptoms. This study therefore assessed the healthcare professionals' knowledge and perception of pain management as well as the prescribing pattern in the management of pain in a university medical facility.

\section{MATERIALS and METHODS}

\section{Study Setting}

This study was conducted at the University of Lagos Medical Center. The center, a secondary health care facility is a 20-bed hospital attending to an average of 83 patients per day made up mainly of students, staff of the university and their family members.

\section{Study Design}

The study was in two parts; a retrospective study of prescription pattern in the management of pain in the hospital and a prospective survey of perception of pain and its management among the hospital caregivers through the use of a selfadministered questionnaire. The population of healthcare givers surveyed comprises doctors, pharmacists, nurses and laboratory scientists.

All prescriptions written at the clinic for a period of twenty eight weeks (June to December 2011) were examined. A total of 16,365 prescription sheets were reviewed and 4,323 prescriptions that had no analgesics were excluded. 50 health care professionals were involved in the cross sectional survey. The questionnaires were pre-tested on a panel comprising two Medical Doctors, two Pharmacists and one Nurse to ensure content validity, reliability, clarity, omissions and errors.

\section{Data Analysis}

The data was presented with descriptive statistics of frequencies and percentages while inferential statistics was employed to test significant associations using SPSS version 20.1 to calculate chi-square with $p$ set at 0.05 .

\section{Ethical Considerations}

Approval for the study was obtained from the education committee of the Medical center. The committee exempted the study from requirement of ethical approval.

\section{RESULT}

This study was conducted at a University medical facility - a secondary health care facility that attends to students, staff of the university and patients from the immediate environs. The twelve thousand and forty-two patients consisted of 6051 females $(50.2 \%)$ and 5991 males $(49.8 \%)$ giving a male:female ratio of $1: 1$. Majority of the patients $(90.80 \%)$ were adolescents and adults from 14years and above.

The average number of prescription with pain medications within the study period was $73.72 \%$ while those without pain medications made up only $26.28 \%$. While the majority of the patients $(64.3 \%)$ received only one pain medication, about $35.65 \%$ of the patients received multiple pain medications as presented in Table 1

Table 1: Pattern of Utilization of Pain Medications.

\begin{tabular}{|c|c|c|c|c|}
\hline Month & $\begin{array}{c}\text { Prescriptions } \\
\text { With Pain } \\
\text { Medications } \\
(\%)\end{array}$ & $\begin{array}{l}\text { Prescriptions } \\
\text { With No Pain } \\
\text { Medications } \\
\qquad(\%)\end{array}$ & $\begin{array}{c}\text { Prescriptions } \\
\text { With Multiple } \\
\text { Pain } \\
\text { Medications } \\
(\%)\end{array}$ & $\begin{array}{c}\text { Prescriptions } \\
\text { With Single } \\
\text { Pain } \\
\text { Medication } \\
(\%)\end{array}$ \\
\hline JUNE & 69.94 & 30.06 & 30.66 & 69.34 \\
\hline JULY & 77.26 & 22.74 & 43.92 & 56.08 \\
\hline AUGUST & 74.77 & 25.23 & 36.99 & 63.01 \\
\hline SEPTEMBER & 72.49 & 27.51 & 33.19 & 66.81 \\
\hline OCTOBER & 76.56 & 23.44 & 43.86 & 56.14 \\
\hline NOVEMBER & 67.89 & 32.11 & 31.65 & 68.35 \\
\hline DECEMBER & 77.11 & 22.89 & 29.29 & 70.71 \\
\hline $\begin{array}{l}\text { Average } \\
\text { Percentage }\end{array}$ & 73.72 & 26.28 & 35.65 & 64.35 \\
\hline
\end{tabular}

The study revealed that pain occurred in association with other illnesses in $74.16 \%$ of the patients and the most commonly prescribed analgesics were the oral non-opioid analgesics $(85.41 \%)$ as presented in Tables 2 and 3. Acetaminophen was the most commonly prescribed analgesic (30\%) followed by Diclofenac tablets/injection (16\%) and Ibuprofen (12\%). 
Orphenadrin/Paracetamol and Diclofenac/Paracetamol combinations were also used.

Table 2: Occurrence of Pain with other Illnesses among Patients.

\begin{tabular}{lcc}
\hline Month & $\begin{array}{c}\text { Patients with Pain with } \\
\text { other Illnesses (\%) }\end{array}$ & $\begin{array}{c}\text { Patients with pain } \\
\text { only (\%) }\end{array}$ \\
\hline June & 90.47 & 9.53 \\
July & 60.92 & 39.08 \\
August & 66.99 & 30.01 \\
September & 74.94 & 25.06 \\
October & 68.43 & 31.57 \\
November & 68.60 & 31.40 \\
December & 88.74 & 11.26 \\
Average Percentage & 74.16 & 25.84 \\
\hline
\end{tabular}

Table 3: Classes of pain medications used in study population.

\begin{tabular}{lccc}
\hline \multicolumn{1}{c}{ Month } & $\begin{array}{c}\text { Non-Opioid } \\
\text { Analgesics } \\
(\boldsymbol{\%})\end{array}$ & $\begin{array}{c}\text { Adjuvant } \\
\text { Analgesics } \\
(\boldsymbol{\%})\end{array}$ & $\begin{array}{c}\text { Opioid } \\
\text { Analgesics } \\
(\boldsymbol{\%})\end{array}$ \\
\hline June & 85.49 & 4.24 & 10.27 \\
July & 87.84 & 4.18 & 7.97 \\
August & 85.79 & 3.09 & 11.12 \\
September & 84.20 & 5.03 & 10.76 \\
October & 85.50 & 2.54 & 11.94 \\
November & 81.94 & 4.94 & 13.11 \\
December & 87.39 & 2.98 & 9.64 \\
Average percentage & 85.41 & 3.92 & 10.67 \\
\hline
\end{tabular}

The Opioid analgesics, Tramadol and Pentazocine were prescribed for $10 \%$ of the patients that visited the health facility (Table 4). Oral dosage forms were commonly prescribed $(91.38 \%)$ while only $3.54 \%$ of patients received pain medication in form of injectables.

Table 4: Types of Analgesics Commonly Prescribed.

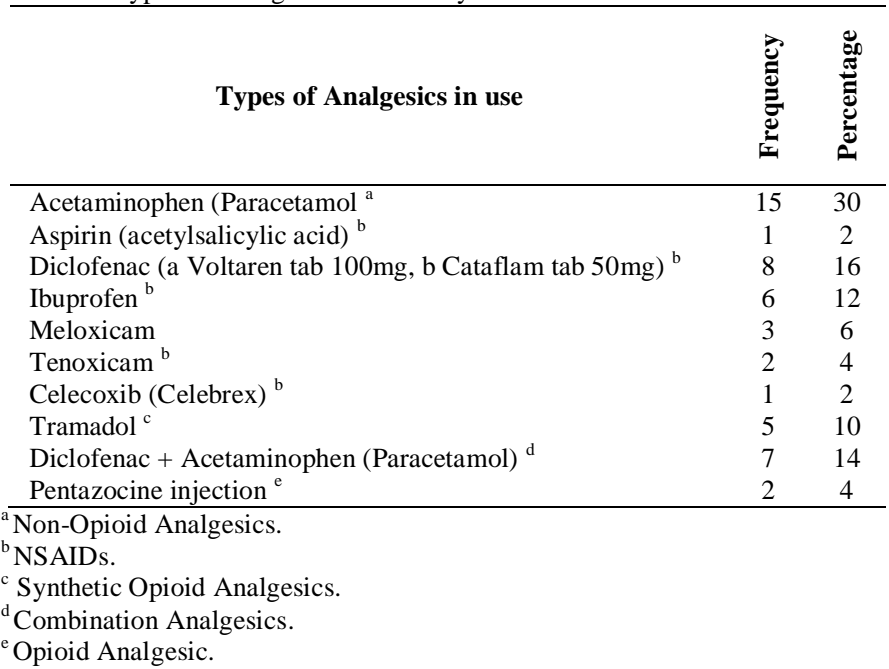

Assessment of healthcare professionals on perception and management of pain revealed mixed views and perceptions; while about $68 \%$ healthcare professionals perceived Pain as not necessarily caused by any other ailment, $62 \%$ of the physicians believed that Pain complaints should be traced to other ailments first before being treated (Table 5). The healthcare professionals that participated in this study believe that pain may occur on its own without necessarily being linked to another ailment and when caused by an ailment, the practitioners were equally divided on whether the pain must be traced to its source before commencement of treatment or not. Their views are captured in the answers given to questions 2, 3, $5 \& 9$ and clearly supported by the response to question 5 .

Table 5: Perception of Pain Management by Healthcare Professionals.

\begin{tabular}{|c|c|c|c|c|c|c|c|}
\hline \multirow[b]{2}{*}{$\mathbf{S} / \mathbf{N}$} & \multirow[b]{2}{*}{ Item } & \multicolumn{6}{|c|}{ Options } \\
\hline & & 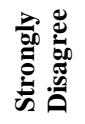 & 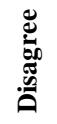 & $\frac{\mathscr{E}}{\vec{E}}$ & 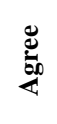 & $\frac{2}{80}$ & 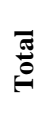 \\
\hline 1 & $\begin{array}{l}\text { Pain can be relieved with } \\
\text { any pain medication }\end{array}$ & 20 & 6 & 12 & 7 & 5 & 50 \\
\hline 2 & $\begin{array}{l}\text { Pain must be traced to its } \\
\text { source before being treated }\end{array}$ & 18 & 4 & 3 & 7 & 18 & 50 \\
\hline 3 & $\begin{array}{l}\text { Pain can be relieved } \\
\text { without necessarily treating } \\
\text { the other ailment that is } \\
\text { present in the patient }\end{array}$ & 6 & 12 & 0 & 42 & 20 & 50 \\
\hline 4 & $\begin{array}{l}\text { All forms of pain can be } \\
\text { relieved with a single pain } \\
\text { killer even if the pain is } \\
\text { severe. }\end{array}$ & 26 & 10 & 2 & 2 & 0 & 50 \\
\hline 5 & $\begin{array}{l}\text { Pain is not necessarily } \\
\text { caused by any other } \\
\text { ailment }\end{array}$ & 3 & 7 & 6 & 12 & 22 & 50 \\
\hline 6 & $\begin{array}{l}\text { There is a standard method } \\
\text { of treating pain irrespective } \\
\text { of the source of pain. }\end{array}$ & 29 & 13 & 5 & 2 & 1 & 50 \\
\hline 7 & $\begin{array}{l}\text { If subsequently a standard } \\
\text { method is developed, it can } \\
\text { handle all forms of pain } \\
\text { even when other ailment } \\
\text { that could cause pain is not } \\
\text { cured yet. }\end{array}$ & 6 & 13 & 6 & 15 & 10 & 50 \\
\hline 8 & Pain can be cured for life. & 32 & 8 & 9 & 1 & 0 & 50 \\
\hline 9 & $\begin{array}{l}\text { Pain complaints should be } \\
\text { traced to other ailment first } \\
\text { before being treated. }\end{array}$ & 33 & 2 & 1 & 21 & 10 & 50 \\
\hline
\end{tabular}

Table 6: Recommendation of Healthcare Professionals on Standard Pain Management.

\begin{tabular}{|c|c|c|c|c|}
\hline 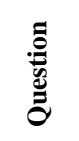 & & Responses (Options) & 或 & 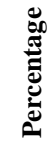 \\
\hline \multirow{10}{*}{ 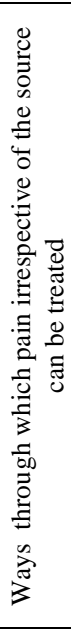 } & $\mathrm{S} / \mathrm{N}$ & RESPONSES & \multirow[b]{2}{*}{32} & \multirow[b]{2}{*}{64} \\
\hline & 1 & $\begin{array}{l}\text { Assess the pain by observing the patient first, } \\
\text { determine the source and then prescribe the } \\
\text { required drug }\end{array}$ & & \\
\hline & 2 & $\begin{array}{l}\text { By prescribing medications first followed by } \\
\text { radiological examinations if the pain subsists }\end{array}$ & 2 & 4 \\
\hline & 3 & $\begin{array}{l}\text { By using my knowledge of pain measure } \\
\text { scales available }\end{array}$ & 3 & 6 \\
\hline & 4 & $\begin{array}{l}\text { All pains requires immediate treatment } \\
\text { regardless of the source or severity }\end{array}$ & 2 & 4 \\
\hline & 5 & $\begin{array}{l}\text { Pains should be treated first with simple } \\
\text { analgesic before other drugs }\end{array}$ & 3 & 6 \\
\hline & 6 & By using pain rate scale if available & 1 & 2 \\
\hline & 7 & $\begin{array}{l}\text { Pain can only be relieved not cured so we } \\
\text { give pain relievers }\end{array}$ & 2 & 4 \\
\hline & 8 & $\begin{array}{l}\text { There is no rigid adherence to standard } \\
\text { treatment but to treat the pain based on type, } \\
\text { location and severity }\end{array}$ & 3 & 6 \\
\hline & 9 & Relieve the pain first before anything & 2 & 4 \\
\hline & & TOTAL & 50 & 100 \\
\hline
\end{tabular}

Calculated chi-square $=21.028$ at $\mathrm{p}=0.05$ 
In a test of significance, the chi-square $\left(\mathrm{x}^{2}\right)$ calculated was 21.028 at $p=0.05$. There was a significant link between pain and other illnesses in the perception of the health practitioners.

$64 \%$ of the healthcare workers recommended the observation of patient and tracing the source of pain before prescribing medication as a standard pain management method. From their response, the health care practitioners were not familiar with the pain measure scale and pain rate scale in pain management ( $6 \%$ and $2 \%$ respectively). The recommendation of the physicians on a standard method of treating pain irrespective of the source of the pain is significant.

\section{DISCUSSION}

The importance of pain as a major worldwide health care problem has been recognized by the World Health Organization (WHO) and the need for further research into pain mechanisms and control was recognized by the U.S. Congress in its declaration of the years 2001-2010 as the decade of Pain Control and Research. This study investigated the pattern of use of analgesics and evaluated healthcare professionals' knowledge and perceptions of pain and its management in a University Medical Center. The study findings revealed a high proportion of patients accessing the facility with pain related symptoms. The population of patients was made up of slightly more women than men. This is in contrast to earlier reports that have indicated that women are at increased risk of experiencing pain due to gender role expectations and the many clinical conditions accompanied with pain which reportedly occur more frequently among females than males. Women also have high health seeking behaviors and greater pain sensitivity (LeResche, 2000, Miu et al., 2004).

Pain is the driving force that leads people to seek treatment (Deyo et al., 2011) and this assertion corroborates the findings in this study where over $70 \%$ of the patients that visited the Medical Centre (average of $73.72 \%$ per month) during the study period had pain complaints and were managed with pain medications. This will account for the high volume of pain prescriptions recorded during the period of the study. The observation in this study confirmed the high likelihood of a relationship between pain and other ailments. In the month of June alone, over $90 \%$ of the patients presented with pain associated with other illnesses while within the six month period of study, an average of $74.16 \%$ patients had pain complaints in association with other ailments. If the underlying disorder is treated effectively, there is the likelihood of the elimination or at least a reduction of the pain. However there were instances of pain occurring alone as reflected in about $25 \%$ of the cases who reported for treatment for pain without having other ailment. Earlier studies on the etiology of pain had posited that pain is traceable to pathological conditions or could be triggered off by physical, mechanical, thermal, electrical or chemical agents (Beers et al., 1999, Kaye et al., 2010). Pain has also been considered the fifth vital sign in disease conditions (Smith et al., 2001, International Association for the Study of Pain 2011). Although there is currently no ideal analgesic for managing pain, several combinations of analgesics were prescribed in this secondary health facility where $40 \%$ of the patients were treated with multiple pain medications. This may expose the patients to the adverse effects of these drugs and encourage poly-pharmacy. Oral non-opioid analgesics formulations (acetaminophen and Nonsteroidal anti-inflammatory agents) were the main stay in the management of pain and the use of opioid analgesics was quite low $(10.67 \%)$. Opioids are usually prescribed in the management of chronic pain and post-surgical conditions. While examining the pattern of use of analgesics, some investigators in Portland found out that about $61 \%$ of the patients were on opioids for back pain, and almost $20 \%$ received long-term opioids (Gordon et al., 2005). In a study carried out in Ilorin and Zaria (Nigeria) a high use of IM injections of opioids $(91.3 \%)$ consisting of pethidine, pentazocine and tramadol were reported. (Kolawole and Fawole, 2003; OgboliNwasor, 2012). The Zaria and Ilorin studies focused on surgical patients in tertiary health facilities while the University Medical Center is a secondary health care facility which did not handle surgeries. The low opioid use in this study could also be attributed to the fact that in most acute clinical settings in Nigeria, opioid analgesics are classified as controlled drugs; hence their use is restricted to avoid misuse, abuse and addiction. However, this restriction have being found to contribute to inadequate control of acute pain in developing countries (Rajagopal et al., 2001).

Acetaminophen (Paracetamol) was the most frequently used analgesic, thus confirming the notion that acetaminophen is the most commonly abused medication to treat even mild pain. Oral dosage forms were mostly prescribed (91.38\%) and only $5.08 \%$ injectables. This pattern conforms to WHO requirements on rational drug prescribing. Since over $70 \%$ of the patients treated in the Medical Centre during the study period received pain medications, there is the need to assess the presence and use of standard clinical guidelines for the prescription of pain medications. This study therefore assessed healthcare professionals' perceptions and views on pain management in this clinical setting and found a mixed viewpoints on required patient level of assessment and line of management. Some of the healthcare professionals (68\%) perceived pain as not necessarily caused by any other ailment but a proportion (62\%) believed that pain complaints should be traced to other ailment first, before being treated. $64.48 \%$ of the physicians perceived that pain can be associated with other illnesses. The Chi-square calculation established that this perception, which linked pain with other ailments was significant (chi-square $\left(\mathrm{x}^{2}\right) 21.028$ at $p=0.05$ ). Pain medications were prescribed for the patients most times without an initial in-depth examination or review of the cause of pain. Majority of the respondents $(62 \%)$ disagreed with the use of a single agent to relieve pain and also believed that pain is a disease that cannot be cured, implying that the patients must continuously be on medications thereby predisposing them to long term adverse effects of analgesics. Evidences have shown that the detection and management of both acute and chronic pain had remained inadequate (Benhamou et al., 2008, Berben et al.,2008, Macrae 
2008, Ogboli-Nwasor et al., 2012). The need for a standard approach to pain management was further explored, $64 \%$ of the respondents agreed that a standard way of treating pain will produce a more effective control and management. They believed that assessing the pain, observing the patient, determining the source of the pain will give a more effective management and better pain control. A test of significance using chi square, showed that this knowledge of having a standard method of treating or managing pain was significant $(p=0.05)$. It has been recommended that a standard approach to pain management should be followed in clinical settings. This should include comprehensive pain assessment, thorough medical history and physical examination, review of systems and pertinent laboratory results, imaging studies and diagnostic tests (Gourlay,2005). A multicenter study in France also found that pain intensity was not sufficiently reassessed and delays in treatment were common and uncontrolled acute pain have being found to not only cause discomfort and suffering but can have unwanted consequences such as delayed healing, increased risk of morbidity, prolonged hospital stay, and the risk of resultant chronic persistent pain (Macrae 2008). No standard procedure was in use in the management of pain in patients at the Medical Center. Inadequate pain management is a powerful stressor and inadvertently triggers relapse. It is a major reason that makes people turn to the use of both licit and illicit drugs, and the use of legal substance such as alcohol to numb the pain. Rational pain care is the right approach for dealing with pain, especially chronic pain and will prevent addiction, overdose, disablement, or even death. It will certainly be very useful especially in the emergency department, the hospital at large and be of huge benefit to the patient.

\section{CONCLUSION}

Pain was a common complaint as revealed by the high percentage of prescriptions with pain medication either singly or in combination with other medications at the University Medical Center. Non-opioid oral formulations (Paracetamol and NSAIDs) were the most commonly prescribed while little or no opioid or its analogues were used. As a consequence there may be reduced quality of therapy, risk of unwanted effects, or patients reverting to self-medication. Health care practitioners had a perceptions that there are connections between pain and other illnesses, therefore treating these underlying illnesses may provide a relief from accompanying pain. The use of standard pain management guidelines and tools was however not familiar hence not in use. The management of pain can be perceived as an enormous public health challenge. Knowledge of healthcare practitioners on pain management should be regularly updated in order to develop strategies to better assess and manage pain for better therapeutic outcomes.

\section{Limitations of the Study}

The study was conducted in only one center hence the number of healthcare providers was limited. The study needs to be extended to health care practitioners in more health facilities before it can be extrapolated for possible policy statements

\section{Financial support and sponsorship: Nil.}

Conflict of Interests: There are no conflicts of interest.

\section{REFERENCES}

Alan D. Kaye, Amir Baluch, and Jared T. Scott. Pain Management in the Elderly Population: A Review. The Ochsner Journal 2010; 10 (3): 179-187.

Apfelbaum J.L, Chen C, Mehta S.S, Gan T.J. Postoperative pain experience: results from a National survey suggest postoperative pain continues to be undermanaged. Anesth Analg 2003;97:534-40.

Beers MH, Berkow R et al., (Ed): Pain. In The Merck Manual of Diagnosis and Therapy 17th Edition. Merck Research Laboratories. 1999:1363ff

Berben. S.A., Meijs. T.H., van Dongen. R.T., van Vugt. A.B., Vloet. L.C., Mintjes-de Groot.J.,J., van Achterberg. T Pain prevalence and pain relief in trauma patients in the Accident and Emergency department. Injury. 2008; 39:578-85

Benhamou D, Berti M, Brodner G et al., Postoperative analgesic therapy observational survey (PATHOS): A Practice Pattern Study in 7 Central/Southern European countries. Pain. 2008; 136: 134-41

Brennan F and Cousins M.J. Pain relief as a human right. Pain: Clinical Updates 2004; XII (5):1-4.

Clark J.D. Chronic pain prevalence and analgesic prescribing in a general medical population. J Pain Symptom Manage. 2002; 23:131-137.

Deyo,R.A, Smith, D.H.M, Eric S. Johnson,E.S, Donovan,M, Tillotson, C.J, Yang, X, Amanda Petrik, A and Dobscha, S.K. Opioids for Back Pain Patients: Primary Care Prescribing Patterns and Use of Services J Am Board Fam Med. 2011; 24(6):1-17

Gordon D.B, Dahl J.L, Miaskowski C, McCarberg B, Todd K.H, Paice J.A, Arthur G. Lipman AG, Bookbinder M, Sanders SH, Turk DC, Carr D.B. American Pain Society Recommendations for Improving the Quality of Acute and Cancer Pain Management. Arch Intern Med. $2005 ; 165: 1574-1580$

Gureje, O., Von Korff M, Simon GE, Gater R., Persistent pain and well-being: a World Health Organization Study in Primary Care. JAMA. 1998; 280(2):147-151

Gureje O, Simon G.E, Von Korff M. A cross national study of the course of persistent pain in primary care. Pain. 2001; 92:195-200.

Gourlay, DL, Heit, HA and Almahrezi, A. Universal Precautions in Pain Medicine: A Rational Approach to the Treatment of Chronic Pain. Pain Medicine.2005; 6(2) 56-61

International Association for the Study of Pain. Pain Clinical Updates, 2011; Vol. XIX, Issue 3 (accessed 27 October, 2015)

Institute of Medicine,"Relieving Pain in America: A Blueprint for Transforming Prevention, Care, Education, and Research" (Washington, DC: National Academy of Sciences, 2011), p. 5. Available at http://www.nap.edu/openbook.php?record_id=13172 (Accessed on $14^{\text {th }}$ October, 2013)

Kolawole IK, Fawole AA Postoperative pain management following caesarean section in University of Ilorin Teaching Hospital (UITH), Ilorin, Nigeria. West Afr J Med. 2003; 22(4):305-309.

LeResche, L. Epidemiologic perspectives on Sex differences in pain. In R. B. Fillingim (Ed), Progress in Pain Research and Management: Vol. 17. Sex, gender and pain; Seattle: IASP press. 2000.

Macrae WA. Chronic post-surgical pain 10 years on. Br J Anaesth; 2008; 101:77-86.

Mantyselka P, Kumpusalo E, Ahonen R, Kumpusalo A, Kauhanen J, Viinamaki H, Halonen P, Takala J: Pain as a reason to visit the doctor: a study in Finnish primary health care. Pain 2001; 89:175-180.

McCaffery M., Beebe A., (1994) Pain: Clinical Manual for Nursing Practice, London Miu.D.K.Y. Chan.T.Y., Chan.M.H. Pain and 
disability in a group of Chinese elderly out-patients in Hong Kong; Hong Kong Med J. 2004; 10(3) 160-65

Ogboli-Nwasor E, Sule S.T, Yusufu L.M.D.Pattern of postoperative pain management among adult surgical patients in a lowresource setting; Journal of Pain Research: 2012; (5)117-120.

Public Law 106-386, Victims of Trafficking and Violence Protection Act of 2000. Title VI, Section 1603, "Decade of pain control and research." (Oct. 28, 2000).

Rajagopal M.R, Joranson D.E, Gilson A.M. Medical use, misuse and diversion of opioids in India. Lancet. 2001; 358:139-43.

Roumie CL, Griffin MR Over-the-counter analgesics in older adults: a call for improved labelling and consumer education. Drugs Aging 2004; 21(8):485-98.

Smith BH, Elliott AM, Chambers WA, Smith WC, Hannaford PC, Penny K The impact of chronic pain in the community. Fam Pract. 2001; 18:292-299,

Stewart WF, Ricci JA, Chee E, Morganstein D, Lipton R. Lost productive time and cost due to common pain conditions in the U.S. workforce. JAMA. 2003; 290:2443- 2454.

\section{How to cite this article:}

Soremekun RO, Ogunjuyigbe OK, Onwuchuluba EE. Pattern of Analgesic use and Perception of Pain Management by Health Care Workers in a Medical Facility. J App Pharm Sci, 2016; 6 (11): 081086. 